\title{
KNOWLEDGE AND ATTITUDE REGARDING INFECTION CONTROL AND STANDARD PRECAUTIONS AMONG HEALTHCARE WORKERS OF RURAL NEPAL
}

\author{
Rajbhandari $A K^{1^{*}}$, Sagtani $R A^{1}$, Thapa $B^{1}$, Adhikari $P^{1}$
}

\section{Affiliation}

1. Assistant Professor, Department of Community Health Sciences, Patan Academy of Health Sciences, Nepal

\section{ARTICLE INFO}

Article History
Received : 29 May, 2018
Accepted : 29July, 2018
Published : 31 August, 2018

C) Authors retain copyright and grant the journal right of first publication with the work simultaneously licensed under Creative Commons Attribution License CC - BY 4.0 that allows others to share the work with an acknowledgment of the work's authorship and initial publication in this journal.

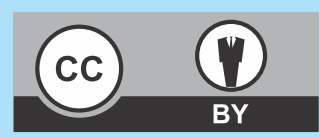

ORA 74

DOI: http://dx.doi.org/10.3126/bjhs.v3i2.20944

\section{* Corresponding Author}

Mr. Ajay Kumar Rajbhandari Assistant Professor

Department of Community Health Sciences

Patan Academy of Health Sciences Nepal

Email: ajayrajbhandari@pahs.edu.np

ORCID: https://org/0000-0002-5315-7584

\section{Citation}

Rajbhandari AK, Sagtani RA, Thapa B, Adhikari P. Knowledge and Attitude Regarding Infection Control and Standard Precautions among Healthcare Workers of Rural Nepal. BJHS 2018;3(2)6: 453-457.

\section{ABSTRACT}

\section{Introduction}

A healthcare associated infection (HCAl) during patient care is an emerging challenge to healthcare service delivery. Transmission of most of these HCAls can be prevented through application of standard precautions which are a set of infection control practices followed during patient care, whether or not they appear infectious or symptomatic.

\section{Objective}

This study aims to assess the existing knowledge and attitude on infection control and standard precautions among healthcare personnel working in peripheral healthcare settings of Nepal.

\section{Methodology}

It was a cross-sectional study and included nine different health facilities in Makwanpur district. Knowledge and attitude regarding infection control and standard precautions were assessed with the help of a self-administered questionnaire on a pre-determined scale. The results are presented as frequency distribution table and valid proportions.

\section{Results}

In the study, $91.9 \%$ of the HCWs agreed that HCAl is caused by micro-organisms that can be transmitted between patients while $51.5 \%$ of them disagreed that HCAI can be caused by micro-organisms carried on the hands of healthcare workers. Majority (98.6\%) of the HCWs believed that the use of gloves, mask and apron reduces the risk of HCAI whereas $13.5 \%$ of HCWs disagreed that gloves should be changed between the examination of different patients. Although $97 \%$ of the HCWs agreed that hand should be washed before and after examining the patient, $17.6 \%$ of them informed that they do not always wash their hands before and after examining a patient.

\section{Conclusion}

Irrespective of limited availability of infection control guidelines, it was found that the knowledge on HCAI control was good and majority of the respondents showed favorable attitude towards infection control and standard precautions.

\section{KEYWORDS}

Healthcare worker, infection control, standard precautions. 


\section{INTRODUCTION}

Healthcare Associated Infection (HCAl) during patient care is an emerging challenge to healthcare service delivery. At any time, over 1.4 million people worldwide are found to be suffering from infectious complications acquired in healthcare settings. ${ }^{1}$ A survey carried out by World Health Organization in 55 hospitals of 14 countries showed that an average of $8.7 \%$ of hospital patients had HCAl. ${ }^{2}$ Such infections leads to increase in disease severity, prolong hospital stay, emotional stress, functional disability and financial burden to the patient or patient party. ${ }^{3}$ In addition to patient safety, it is also a major concern towards healthcare workers (HCWs) who are involved in the patient care and are at high risk of HCAl.

Transmission of most of these infections can be prevented through application of Standard Precautions (SPs), the precautions that healthcare workers must follow on all patients at all times, irrespective of their diagnosis or infectious status. ${ }^{4,5}$

In Nepal, little is known about knowledge of HCWs on Infection Control (IC) and SPs. Further, most of these studies are primarily based on workers from urban tertiary care centers. $^{6}$ Thus, this study was conducted to assess the existing knowledge and attitude of healthcare personnel working in peripheral healthcare settings of Nepal towards HCAls, IC and SPs.

\section{METHODOLOGY}

This was a cross sectional study carried out among 74 healthcare workers from nine healthcare facilities in 2015. Makwanpur, being the study district of Patan Academy of Health Sciences for its community based learning and education activities, was considered for this study. Included healthcare facilities represent every category of the rural health-care settings available in Makwanpur ranging from former sub-health post (SHP), Health Post (HP), Primary Health Care Centers (PHCC) to district hospital. All the HCWs from district hospital and at least two health facilities of each category were randomly selected through nonprobability sampling. All HCWs who came in direct contact with patients or their body fluids were included in the current study.

Knowledge and attitude regarding $\mathrm{HCAl}$ control and standard precautions were assessed with the help of a validated self-administered questionnaire on a predetermined scale (agree, disagree and uncertain) which has been previously used in Nepalese settings. ${ }^{6}$ The questionnaire was modified and translated to fit the local context before use. Also, an observation checklist ${ }^{6}$ was used to access the available facilities in the institution for HCAI prevention and control.

Data obtained from the survey questionnaire and the observation checklist was entered into a Microsoft Excel spreadsheet. The results of the survey were presented in frequency distribution table and valid proportions following analysis with the help of Statistical Package for
Social Sciences (SPSS) version 16.0

Ethical approval was obtained from Institutional Review Committee of Patan Academy of Health Sciences, an accredited body by Nepal Health Research Council. Informed verbal consent was received from the respondents before on-site data collection. Confidentiality and anonymity of the study participants was assured and maintained.

\section{RESULTS}

\section{Available facilities for infection control}

Majority of the respondents (95.7\%) informed that they have regular supply of gloves in their unit or department. However, about one-fourth of the respondents mentioned that apron was not available in their respective unit/ departments. About half of the respondents stated that they did not have regular supply of masks while more than fifty percent of respondents stated that they did not have alcohol based hand rub available in their unit. Provision of container for safe disposal of infectious waste (78.6\%) and sharp waste $(89.9 \%)$ was reported by more than threefourths of the respondents. Recognizing a worldwide need to improve hand hygiene in health care facilities, the World Health Organization launched a guidelines on hand hygiene in health care in April 2006. ${ }^{7}$ But half (49.3\%) of the surveyed health facilities in Makwanpur did not have infection control guidelines. (Table 1)

$\begin{array}{lc}\begin{array}{l}\text { Table 1: Availability of item/facility in health facilities for } \\ \text { infection control }\end{array} & \begin{array}{l}\text { Available (in \%) } \\ \text { Item/ Facilities }\end{array} \\ \text { Gloves } & 95.7 \\ \text { Masks } & 52.2 \\ \text { Aprons } & 75.4 \\ \text { Hand washing basin } & 90.0 \\ \text { Water Supply } & 95.7 \\ \text { Soap } & 97.1 \\ \text { Alcohol Hand rubs } & 46.4 \\ \text { Container for safe disposal of infectious waste } & 78.6 \\ \text { Container for safe disposal of sharp waste } & 89.9 \\ \text { Infection control guideline } & 49.3\end{array}$

Knowledge on use of Personal Protection Equipment (PPE)

In the study, $97.3 \%$ of the HCWs agreed that hand should be washed before and after examining the patient. Majority of HCWs agreed that gloves should be used while examining the patient. Interestingly, $2.7 \%$ of them disagreed that hands should be washed after use of gloves. More than one-tenth (13.5\%) of HCWs disagreed that gloves should be changed between patients. Majority (98.6\%) of the HCWs believed that the use of gloves, mask and apron reduces the risk of HCAl and were also aware of the fact that HIV can be transmitted by infectious needle stick. Also, around three percent of HCWs disagreed or were uncertain about transmission of Hepatitis B by needle stick injury. (Table 2) 
Table2: Knowledge among HCWs of Makwanpur district on use of PPE $(n=74)$

Knowledge regarding PPE
Response (in \%)

Agree

97.3

89.2

95.9

77.0

98.6

98.6

97.2

Disagree
2.7

9.4

2.7

13.5

1.4

1.4

1.4
Uncertain

Hands should be washed before and after examining the patient

Gloves should be used while examining the patient

Gloves should be changed between patients

The use of gloves, mask and apron reduces the risk of infection

HIV can be transmitted by infectious needle stick

Hepatitis B can be transmitted by needle stick injury
0.0

1.4

1.4

9.5

0.0

0.0

1.4

\section{Knowledge on infection control}

Less than half (44.3\%) of the HCWs had attended training on infection control. These trainings were given by several agencies including district public health office, Family Planning Association of Nepal, Marie Stopes, Population Service International, Sparsh Nepal, etc, and duration of the training varied from 1-15 days. Majority (91.9\%) of the HCWs agreed that HCAl is caused by micro-organisms that can be transmitted between patients, however, more than half $(51.4 \%)$ of them disagreed that HCAl can be caused by micro-organisms carried on the hands of healthcare workers. Nearly half of them disagreed that a patient in critical clinical condition increased the risk of HCAI. In total, almost one-third of them did not accept that inappropriate use of antibiotics can raise the risk of HCAI. In addition, almost one-fifth $(20.3 \%)$ of them disagreed with the fact that invasive devices, such as urinary catheterization, can increase the risk of HCAl. Significant numbers (13.5\%) of health workers were uncertain on whether such invasive devices could contribute in risk of HCAl. All the HCWs believe that patient and visitors should be informed about possibilities of transmission of HCAl including its prevention measures. However, one-tenth of the respondents were still reluctant and uncertain on partial prevention of HCAI through strict compliance to infection control protocols. (Table 3).

While assessing the attitude of HCWs regarding infection control measures, it was found that almost one-fifth $(17.6 \%)$ of the health workers washed there hands only at times before and after examining a patient. Only two-third (29.7\%) of the total health workers sometimes dried their hand after getting their hand washed while $2.7 \%$ did not dry at all. More than one third (39.2\%) of HWs did not always wear a waterproof apron when there is the possibility of blood or other body fluids splashing on their clothes. Similarly, about one fourth (24.3\%) of the HCWs did not always wear face mask when there is the possibility of splashing of blood or other body fluids. Almost all the health workers agreed that needles and other sharp objects need to be collected into the designated sharp container however, more than two thirds (67.6\%) never recapped used needles. (Table 4)
Table 3: Knowledge on Infection Control among HCWs of Makwanpur district $(n=74)$

Statement

HCAl is caused by micro-organisms that can be transmitted between patients

HCAI can be caused by micro-organisms carried on the hands of health care personnel

Routine hand decontamination reduces risk of infection in patient

Routine hand decontamination reduces risk of infection in healthcare workers

Hand decontamination between each patient protects both staff and patient

Invasive devices can increase the risk of HCAl

Hospital instrument should always be sterilized

A patient in a critical clinical condition increases the risk of HCAI

Inappropriate use of antibiotics can increases the risk of HCAl

HCAI can be partially prevented by strict compliance to infection control protocols
Response (in \%)

Agree Disagree Uncertain

$\begin{array}{lll}91.9 & 6.7 & 1.4 \\ 48.6 & 51.4 & 0.0 \\ 91.9 & 8.1 & 0.0 \\ 97.3 & 2.7 & 0.0 \\ 98.6 & 1.4 & 0.0 \\ 66.2 & 20.3 & 13.5 \\ 97.2 & 1.4 & 1.4 \\ 50.0 & 43.2 & 6.8 \\ 51.4 & 37.8 & 10.8 \\ 86.5 & 9.4 & 4.1\end{array}$


Table 4: Attitude of HCWs of Makwanpur district towards infection control measures. $(n=74)$

Statement

Response (in \%)

Always Sometimes Never

I wash my hand before and after examining a patient.

82.4

17.6

0.0

I dry my hands after hand washing

67.6

29.7

2.7

I wear gloves whenever there is possibility of exposure to blood or other body fluids

I wash my hands after removing disposable gloves

4.1

I wear a waterproof apron whenever there is possibility of blood

or other body fluids splashing on my clothes

I wear a mask on my face whenever there is possibility of blood

or other body fluid splashing

16.2

I wear a clean washed uniform everyday

I dispose of all the contaminated items into a disposal bag.

1.4

I immediately wipe up all spills of blood and any other body fluids

1.4

I cover my broken skin before coming to work.

94.6

I consume food and beverages in patient/resident care areas

I put used needles and other sharp objects into the designated

sharp container

98.6

0.0

I recap used needles

\section{DISCUSSION}

The primary goal of the present study was to assess the knowledge and attitude of HCWs on IC and SPs. Studies have reported different levels of knowledge related to IC in HCWs, and the proportion of HCWs who were aware of these practices ranged from $16-75 \%{ }^{8,9}$

The key finding of the study was that the knowledge scores were high whereas practice was moderately high except in few procedures. The most astonishing finding of this study was that HCWs have a positive attitude toward infection control guidelines and recognize its importance. This finding is similar to the studies carried out in Saudi Arabia that have assessed attitudes toward hand hygiene in medical settings. ${ }^{10,11}$ In our study $97.3 \%$ of them never consumed food in patient care area which was a very healthy practice related to the hygiene.

A study in Jordan reported around $49.6 \%$ of HCWs had knowledge of infection control..$^{12}$ In contrary, a similar kind of study conducted in Nepal stated that only $16 \%$ of HCWs had knowledge of infection control. ${ }^{6}$ A study in India which is consistent with our study, had reported around $75.5 \%$ of staff nurses at a tertiary care hospital had knowledge of infection control. ${ }^{9}$

In the present study, HCWs were found having adequate knowledge regarding hand washing. Attributable reasons could be sufficient training for infection control measures, regular and adequate supply of PPE, and carefully implementing them in daily practice. $97.3 \%$ of the HCWs knew about hand washing practices before and after the patient's examination. Amongst them, only $82.4 \%$ (mentioned that they) washed their hand. Our study is consistent with the study conducted among the nurses in a tertiary care hospital of India where $93 \%$ of respondent reported that they wash their hands before and after attending to each patient. ${ }^{8}$ This study was also similar to a study carried in Birmingham teaching hospitals ${ }^{13}$ Nearly, $90 \%$ knew about the use of gloves but surprisingly almost 95.5\% used it in need which was a good practice. Knowledge can be said as adequate as nearly more than $90 \%$ of workers had knowledge about the use of different PPE. Knowledge regarding changing of gloves between patients was seen in $77 \%$. Different studies have extensively reported suboptimal and non-uniform adherence to standard precautions by HCWs in both developed as well as in developing countries. ${ }^{14-16}$ Another study from North India had reported that $40 \%$ of HCWs recapped needles and only $32 \%$ wore eye protection during their procedures. ${ }^{17}$ In our study, approximately $25.7 \%$ recapped needles, $75.7 \%$ of the HCW's used mask and $60.8 \%$ used apron which is consistent with previous studies. Nearly $70 \%$ of HCWs always complied with different precautions methods of infection control in our study which is consistent with the studied carried out in Jordan. ${ }^{12}$ Similar study in India stated the mean reported infection control practice to be $57.5 \% .{ }^{9}$ It included washing hands, wiping up the floor immediately, wearing gloves, apron, masks, clean uniform and disposing needles and foods correctly.

\section{CONCLUSION}

It was found that 49.3 percent of the surveyed health facilities in Makwanpur do not have any infection control guideline available in their institution and 55.7 percent of $\mathrm{HCW}$ s have not received any training on HCAl control. Nevertheless, their knowledge on infection control was 
good and all respondents showed favorable attitudes to infection control and hand hygiene. Majority of them agreed that they should wash their hand before and after examining the patient. They also agreed that glove should be used while examining the patient and hand should be washed even after gloves are used. However, around half of the respondents still do not agree with the fact that HCAl can be caused by microorganisms carried on the hands of health care personnel.

\section{RECOMMENDATIONS}

In order to reduce the risk of HCAls HCWs should be oriented and equipped with requisite knowledge, skills and attitudes for good infection control practices at healthcare settings. Arrangement of mandatory training provision by the concerned authorities is recommended for every HCWs on infection control measures before these workers start offering their services. Also, an infection prevention manual containing instructions and practices for patient care should be made readily available in every healthcare setting, and should be updated in a timely fashion. Provision of periodic refreshment training on infection control needs to be integrated with regular national public health programs.

\section{REFERENCES}

1. Tikhomirov E. World Health Organization program for the control of hospital infections. Chemiotherapia, WHO.1987, 3:148- 151. PMID: 3607925

2. Mayon-White RT et al. An international survey of the prevalence of hospital-acquired infection. J Hosp Infect, 1988, 11 (Supplement A):43-48. PMID:2896744

3. Ponce-de-Leon S. The needs of developing countries and the resources required. J Hosp Infect, 1991, 18 (Supplement):376-381. DOI: https://doi.org/10.1016/0195-6701(91)90044-9

4. Centers for Disease Control. Guideline for isolation precautions: preventing transmission of infectious agents in healthcare settings. 2007. May 2018, assess at https://www.cdc.gov/infectioncontrol/ pdf/guidelines/isolation-guidelines.pdf

5. World Health Organization, Regional Office for South East Asia. Guidelines on prevention and control of hospital associated infections. New Delhi: WHO, 2002. April 2018, assess at http://apps.searo.who.int/PDS_DOCS/B0007.pdf

6. Paudyal P, Simkhada P, Bruce J. Infection control knowledge, attitude, and practice among Nepalese health care workers. American Journal of Infection Control 2008;36:595-597. PMID: 18926315

7. World Health Organization, WHO Guidelines on Hand Hygiene in Health Care (Advanced Draft). Geneva: WHO; 2006. available at: http://www.who.int/patientsafety/information_centre/Last_April _versionHH_Guidelines\%5B3\%5D.pdf

8. Sodhi K, Shrivastava A, Arya M, Kumar M. Knowledge of infection control practices among intensive care nurses in a tertiary care hospital. J Infect Public Health. 2013;6(4):269-275. PMID: 23806701

9. Taneja J, BibhaBati M, Aradhana B, Poonam L, Vinita D, Archana T. Evaluation of knowledge and practice amongst nursing staff toward infection control measures in a tertiary care hospital in India. Canadian Journal of Infection Control 2009;24:104-107. PMID: 19697535

\section{LIMITATIONS OF THE STUDY}

Although this research tries to assess the prevailing knowledge and attitudes of HCWs towards IC and SPs, there were few study limitations. Some of the eligible respondents who were not physically present on the day of survey were not included in the study. Also, as the study sites were purposively selected and data were selfreported, this limits the precision of the study and the study findings may hold limited external validity.

\section{ACKNOWLEDGEMENT}

The authors would like to acknowledge entire healthcare workers involved in the study for their time and efforts. The study team is in debt to Department of Community Health Sciences, Patan Academy of Health Sciences for allowing an institutional support to conduct the study.

\section{CONFLICT OF INTEREST}

Authors declared no conflict of interest.

\section{FINANCIALDISCLOSURE}

None

10. Hamadah R, Kharraz R, Alshanqity A, AlFawaz D, Eshaq AM, Abu-Zaid A, et al. Hand hygiene: Knowledge and Attitudes of Fourth-Year Clerkship Medical Students at Alfaisal University, College of Medicine, Riyadh, Saudi Arabia. Cureus 2015;7-10. PMID:26430584

11. Amin TT, Al Noaim KI, Bu Saad MA, Al Malhm TA, Al Mulhim AA, Al Awas $M A$, et al. standard precautions and infection control, medical students' knowledge and behavior at a Saudi university: The need for change. Glob J Health Sci 2013;5:114-125. PMID: 23777728

12. Darawad MW, Al-Hussami M. Jordanian nursing students' knowledge of, attitudes towards, and compliance with infection control precautions. Nurse Education Today 2012;July. PMID: 22789874

13. Stein AD, Makarawo TP, Ahmad MF (2003) A survey of doctors' and nurses knowledge, attitudes and compliance with infection control guidelines in Birmingham teaching hospitals. J Hosp Infect 54: 68-73. PMID: 12767850

14. Kermode M, Jolley D, Langkham B, Thomas MS, Crofts N. Occupational exposure to blood and risk of bloodborne virus infection among health care workers in rural north Indian health care settings. American Journal of Infection Control 2005;33:34-41. PMID: 15685133

15. Tadesse M, Tadesse T. Epidemiology of needlestick injuries among health-care workers in Awassa City, Southern Ethiopia. Tropical Doctor 2010;40:111-113. PMID: 20305110

16. Knight VM, Bodsworth NJ. Perceptions and practice of universal blood and body fluid precautions by registered nurses at a major Sydney teaching hospital. Journal of Advanced Nursing 1998;27:746751. DOI: https://doi.org/10.1046/j.1365-2648.1998.00600.x

17. Kermode M, Jolley D, Langkham B, Thomas MS, Holmes W, Gifford SM. Compliance with Universal/Standard and transmission based precautions among health care workers in rural north India. American Journal of Infection Control 2005;33:27-33. PMID: 15685132 